\title{
THERAPEUTIC IMPACT OF BERRIES (MORUS ALBA AND MORUS RUBRA) FRUIT EXTRACT IN THE REGRESSION OF HIGH-FAT DIET-INDUCED CARDIAC DYSFUNCTION IN RATS
}

\author{
FAROUK K EL-BAZ1* , HANAN F ALY ${ }^{2}$, HOWAIDA I ABD-ALLA ${ }^{3}$, DALIA B FAYED ${ }^{2}$
}

${ }^{1}$ Department of Plant Biochemistry, National Research Centre, 33 El Bohouth St. (Former El Tahrir St.), Dokki, Giza, P.0.12622, Egypt. ${ }^{2}$ Department of Therapeutic Chemistry, National Research Centre, 33 El Bohouth St. (Former El Tahrir St.), Dokki, Giza, P.0.12622, Egypt. ${ }^{3}$ Department of Chemistry of Natural Compounds, National Research Centre, 33 El Bohouth St. (Former El Tahrir St.), Dokki, Giza, P.0.12622, Egypt. Email: fa_elbaz@hotmail.com

Received: 12 March 2018, Revised and Accepted: 13 April 2018

\section{ABSTRACT}

Objective: The aim of the present study is to investigate the effect of Morus alba (MA) and Morus rubra L. (MR) fruit extract on obesity-induced cardiac dysfunction and fibrosis in cardiac tissue.

Methods: Seventy male Wistar albino rats were randomly divided into five groups of ten rats each. MA and MR have been administered for 6 weeks in obese rats induced by high-fat diet (HFD). Adiponectin, glucagon, troponin, plasminogen activator inhibitor, cell adhesion molecules-1 (intracellular and vascular respectively), C-reactive protein, collagen type II and collagen alpha-1 (III) chain, and lipoxygenase activity were also estimated in serum of obese rats. Histopathological investigation of cardiac tissue was carried out.

Results: MA and MR treatments significantly normalized cardiac dysfunction biomarkers as well as cardiac fibrosis as examined by histopathological examination with higher percentage of improvement for MR extract.

Conclusion: Hence, it could be concluded that MA and MR extracts have useful effects on obesity-associated cardiac diseases through lipid metabolism regulation, cardiac functions and reversed cardiac fibrosis.

Keywords: Mulberry fruit, Cardiac dysfunction, Cardiac fibrosis, Obesity.

(C) 2018 The Authors. Published by Innovare Academic Sciences Pvt Ltd. This is an open access article under the CC BY license (http://creativecommons. org/licenses/by/4. 0/) DOI: http://dx.doi.org/10.22159/ajpcr.2018.v11i7.25859

\section{INTRODUCTION}

It was found that excess free fatty acids (FFAs) can enhance the response to oxidative stress, which is mechanism implicated obesity, cardiovascular alterations, and cancers [1]. Moreover, fat mass expansion leads to infiltration of macrophage in adipose tissue and pro-inflammatory cytokine production accompanied by an antiinflammatory cytokines suppression, which is ultimately connected with the obesity development-related comorbidities. Hence, chronic low-grade inflammation and oxidative stress occur as a result of the dysregulation of adipokines and infiltration of inflammatory cells in adipose tissue [1]. Thus, endothelial cell dysfunction occurs as a leading cause of oxidative stress and systemic inflammation, resulting in insulin resistance, diabetes, and atherosclerosis [1]. Most current drugs for obesity have adverse side effects. Hence, the approach to new drugs through natural products has proved to be the single most successful strategy for the discovery of new drugs [2]. Mulberry leaf and fruit have been a part of traditional medicine for a long time and have been used to prevent or treat obesity, diabetes, and dyslipidemia [3]. It is a medicinally important plant belonging to genus Morus that is widely distributed in India, China, Japan, North Africa, Arabia, South Europe, etc. [4]. Several studies have also declared that mulberry leaves suppress the activation of nuclear factor kappa-light-chain-enhancer of activated B cells (NF-kB) stimulated by tumor necrosis factor alpha (TNF-a) in vascular endothelial cells and regulate the inflammatory response and oxidative stress by inhibiting nitrite and thiobarbituric acid production reactive substances in blood and tissues [5]. Anthocyanins in mulberry fruit can trap free radicals and decrease the oxidation of low-density lipoprotein (LDL) [1]. In addition, mulberry fruit ameliorates inflammation induced by lipopolysaccharide (LPS) in mouse and arthritic rats [1].
The mulberry fruits (Morus alba L. [MA] and Morus rubra [MR]) distributed widely in Asia as a food containing potential health benefits beyond the traditional nutrients they provide [6]. It is rich in polyphenolic compounds including rutin, quercetin, and 1-deoxynojirimycin (DNJ). Hence, it has been medicated several diseases including dyslipidemia [7], diabetes [8], fatty liver [6], and hypertension diseases [8]. Besides, the mulberry fruits induce enzymatic antioxidant in diabetic models [8]. However, few studies pay particular attention to the mechanism in which fruits of the mulberry attenuate lipogenesis, lipolysis, and fibrosis in obese models induced by HFD. Hence, the aim of the present research is to investigate whether the fruit extract of mulberry (MA and MR) could improve cardiac dysfunction and fibrotic cardiac tissue in HFD-induced obesity in rats.

\section{MATERIALS AND METHODS}

Collection of plant material

Fresh fruits of white MA and purple MR were collected in the Delta region, Egypt. The berries were selected according to uniformity of shape and color. The identification of the plant was confirmed by Therese Labib, Herbarium Section, El-Orman Botanical Garden, Giza, Egypt. The fresh fruit samples were cleaned, stored in polyethylene bags, and frozen at $-20^{\circ} \mathrm{C}$, till further use.

Preparation of extracts for bioassays

The fresh fruits of each species (200 g) were extracted separately with $700 \mathrm{~mL}$ of $70 \%$ aqueous ethanol for $3 \mathrm{~h}$, on an orbital shaker in the dark at room temperature. Each extract was separated by centrifugation $(13,000 \times g, 10 \mathrm{~min})$, the supernatant was taken, the residue was resuspended in $50 \mathrm{~mL}$ of the same solvent, and the mixture was again 
separated by centrifugation. The two resulting supernatants were then combined and concentrated under reduced pressure at $40^{\circ} \mathrm{C}$ till dryness to get 2.54 and $2.39 \%$ of crude ethanol extract of MA and MR, respectively. The residues were stored in the dark at $-20^{\circ} \mathrm{C}$.

\section{Biological assay}

\section{Experimental animals}

Male albino rats $(n=70)$ weighing $150 \pm 10 \mathrm{~g}$ were obtained from the Animal House of the National Research Centre (NRC). Animals were quarantined and allowed to acclimate for 10 days before beginning experimentation. They were housed 10 per cage under temperaturecontrolled environment $\left(26-29^{\circ} \mathrm{C}\right)$ with a fixed light/dark cycle with free access to water and food. All procedures of the present study were performed according to the Ethical Committee of the NRC, Egypt, provided that the animals will not suffer at any stage of the experiment.

\section{Induction of obesity in rats}

Obesity was induced in rats according to the method of Adaramoye et al. [9] by feeding rats HFD of lard. Cholesterol was orally administrated at a dose of $30 \mathrm{mg} / 0.3 \mathrm{~mL}$ olive oil $/ \mathrm{kg}$ animal 5 times a week for 12 consecutive weeks. Lard fat was mixed with normal diet (1 kg of animal lard was added to $5 \mathrm{~kg}$ of normal diet). The occurrence of obesity was determined by measuring body weight gain percentages, visceral, and fecal fat percentages.

\section{Doses and routes of administration}

Obese rats received an oral dose of $2 \mathrm{mg} / \mathrm{kg}$ body weight dissolved in distilled water of the anti-obesity reference drug, orlistat (OR) $(12 \mathrm{mg} / \mathrm{kg})$ for 6 weeks [10]. Purple and white berry ethanol extracts were administered orally for 6 weeks in a dose of $300 \mathrm{mg} / \mathrm{kg}$ body weight [11].

\section{Biochemical measurements}

Various biochemical parameters were measured including adiponectin. Measurement of serum adiponectin levels gives us important formation on the role of adiponectin in the regulation of glucose and/or lipid metabolism. The rat adiponectin ElIZA kit was used for quantitative determination of adiponectin in rat serum. Glucagon enzyme immunoassay (EIA) kit is an in vitro quantitative assay for detecting glucagon peptide based on the principle of competitive EIA. Troponin rats' cardiac troponin I was measured in serum using ELIZA kit. Plasminogen activator inhibitor (PAI-1), intracellular and vascular cell adhesion molecules (ICAM and VCAM), were qualitatively determined in serum of rats by ELIZA. Rat C-reactive protein (CRP) was quantitative measured in rat serum using ELIZA. Rat collagen type II (Col II) and collagen alpha-1(III) chain (Col 3A1) were measured in rat serum by ELIZA kit. Lipoxygenase activity (LOX) was measured in serum using fluorometric method.

\section{Experimental design}

Seventy male Wistar albino rats (15-16 weeks old) weighing at $150 \pm 10 \mathrm{~g}$ (mean \pm SD) were used. Weight of rats was on the day received from supplier. After adaptation period to the environment, the rats were randomly divided into seven groups ( $n=10 /$ group) as follows: Group (1) is the normal diet (ND). Groups (2) and (3) are ND treated with $300 \mathrm{mg} / \mathrm{kg} \mathrm{BW}$ of MA and MR extracts for 12 consecutive weeks (control ND/MA and control ND/MR, respectively). Group (4) is the HFD-treated rats for 112 consecutive. Groups (5) and (6) are obese rats treated for 6 weeks with $300 \mathrm{mg} / \mathrm{kg}$ body weight of ethanolic extract of white and purple berry (HFD/MA and HFD/MR, respectively). Group (7) is the obese rats treated for 6 weeks with antiobesity standard drug OR (12 mg/kg body weight) (HFD/OR). Health conditions of all rats were monitored daily, and no adverse events were observed throughout the study. At the beginning of the experiment, the weight of all rats was recorded at $(150 \pm 10.0 \mathrm{~g})$ (weight of rats after 10 days of acclimatization). All experiments and biochemical analysis were conducted using 70 rats with triplicate measurements. The permission to conduct this study was according to the Ethics of NRC, Egypt.

\section{Blood samples}

Blood samples were obtained following an overnight fasting state at the end of treatment (week 12) at 8 a.m. Samples were withdrawn from a cubital vein into blood tube. Immediately stored on ice at $4^{\circ} \mathrm{C}$. The serum was then separated from the cells by centrifugation at $3000 \mathrm{rpm}$ for $10 \mathrm{~min}$, and they were stored until analyzing at $-80^{\circ} \mathrm{C}$ [12]. After 12 and 18 weeks of treatment, all the rats were sacrificed by decapitation and heart was removed for biochemical analysis of antioxidant.Part of heart was fixed in formalin (10\%) for histopathological examination.

\section{Histological investigation}

Cardiac tissue slices were fixed in $10 \%$ buffer formalin. After fixation, paraffin 4 pm thick sections were taken and stained by hematoxylin and eosin [13].

\section{Statistical analysis}

The data between the different groups were compared using SPSS computer program version 8 coupled with costate computer program, where unshared letters are statistically significant at $\mathrm{p} \leq 0.05$.

\section{RESULTS}

Table 1 demonstrates a significant increase in adiponectin and troponin levels with percentages reached to $83.73 \%$ and $125.55 \%$, respectively, in obese rats, while significant reduction in glucagon level (54.67\%) was recorded. Marked amelioration in adiponectin, glucagon, and troponin I was detected upon treated obese rats with both MA and MR extracts. Higher percentage of improvement for MR extract $(56.33,13.20$, and $89.90 \%$, respectively, for adiponectin, glucagon, and troponin I) compared to standard drug.

Table 2 shows a significant increase in serum levels of ICAM, VCAM, and CRP in obese rats induced by HFD with percentages reached to 168.04, 251.82, and 105.03\%, respectively. Using of MA and MR extract therapy to obese rats indicated normalization in all biomarkers under investigation with higher percentages of improvement for MR (123.64, 75.55 , and $60.76 \%$, respectively, for ICAM, VCAM, and CRP), compared to standard anti-obesity drug.

Table 3 demonstrates a significant increase in Col II and Col3AI and LOX in serum of obese rats with percentages $121.67,144.10$, and $124.00 \%$, respectively. Noticeable amelioration was recorded in the serum levels of obese rats upon treated with both MA and MR compared to standard drug.

\section{Histopathological examination}

Histopathological examination of rat cardiac tissue of control and control treated with MA and MR showed the normal histological structure of the myocardium bundles (Photomicrographs 1 and 2), while photomicrograph of cardiac obese rats induced by HFD demonstrated fibrosis and severe congestion in the myocardial blood vessels (Photomicrographs 3 and 4). Medicated obese rats with MA and MR or OR declared no histopathological alterations in cardiac tissue (Photomicrographs 5-7).

\section{DISCUSSION}

The current results present higher adiponectin serum levels, in HFD rats. This finding is in a parallel with the results of Davidson et al. $[14,15]$ who reported an increase in adiponectin plasma levels post 24 and 32 weeks of HF diet supplementation. These could be explained on the basis of; adiponectin is renowned, by its sensitizing action of insulin. However, obesity may produce a fail on adiponectin signaling (resistance of diponectin). However, Marques et al. [16] showed that adiponectin plays a role in the decrease of insulin sensitivity happened by HFD and illustrated that hyperglycemia initiated by the HFD was associated with linked by a decrease in gene expression of adiponectin in the adipose tissue while did not cause a reduction in the serum levels of adiponectin, speculating that there is a compensative influence of the other depots of fat on serum levels of adiponectin. Previously, it 
Table 1: Effects of MA and MR on adiponectin, glucagon, troponin, and PAI-1 in obese rats and therapeutic groups

\begin{tabular}{|c|c|c|c|c|c|c|c|}
\hline \multirow[t]{2}{*}{ Markers } & \multicolumn{7}{|l|}{ Groups } \\
\hline & Control & Control/MA & Control/MR & HFD & HFD/MA & HFD/MR & HFD/OR \\
\hline Adiponectin (ng/ml) & $15.00^{\mathrm{a}} \pm 0.34$ & $15.34^{\mathrm{a}} \pm 1.00$ & $15.67^{\mathrm{a}} \pm 1.23$ & $27.56^{\mathrm{b}} \pm 0.92$ & $21.32^{\mathrm{c}} \pm 0.65$ & $19.11^{\mathrm{c}} \pm 0.44$ & $20.00^{c} \pm 0.65$ \\
\hline$\%$ improvement & & & & - & 41.60 & 56.33 & 50.40 \\
\hline Glucagon (Pg/ml) & $12.20^{c} \pm 0.90$ & $12.90^{c} \pm 0.12$ & $12.65^{\mathrm{c}} \pm 0.10$ & $5.53^{\mathrm{d}} \pm 0.87$ & $7.82^{\mathrm{e}} \pm 0.67$ & $7.14^{\mathrm{e}} \pm 0.99$ & $7.15^{\mathrm{e}} \pm 1.09$ \\
\hline$\%$ change & - & 3.69 & 3.68 & 54.67 & 35.90 & 41.48 & 41.39 \\
\hline$\%$ improvement & & & & & 18.77 & 13.20 & 13.28 \\
\hline Troponin I (Pg/ml) & $40.00^{\mathrm{i}} \pm 4.32$ & $40.54^{\mathrm{i}} \pm 2.90$ & $41.65^{\mathrm{i}} \pm 4.22$ & $90.22^{\mathrm{f}} \pm 5.11$ & $60.51^{\mathrm{K}} \pm 5.33$ & $54.26^{\mathrm{K}} \pm 7.80$ & $67.45^{j} \pm 6.78$ \\
\hline$\%$ change & - & 1.35 & 4.13 & 125.55 & 51.28 & 35.65 & 68.63 \\
\hline$\%$ improvement & & & & & 74.28 & 89.90 & 56.92 \\
\hline PAI-1 (Pg/ml) & $12.80^{\mathrm{a}} \pm 0.90$ & $12.00^{\mathrm{a}} \pm 1.12$ & $12.35^{\mathrm{a}} \pm 1.43$ & $23.00^{\mathrm{a}} \pm 2.11$ & $17.24^{\mathrm{a}} \pm 1.33$ & $15.52 \pm 1.33$ & $16.00^{c} \pm 1.25$ \\
\hline$\%$ change & & 6.25 & 3.52 & 79.69 & 34.69 & 21.25 & 25.00 \\
\hline$\%$ improvement & & & & & 45.00 & 58.43 & 54.68 \\
\hline
\end{tabular}

ND: Normal diet, ND/MA and ND/MR: Rats feed normal diet and treated orally with white MA and purple MR extract for 6 weeks. HFD/MA and HFD/MR: Rats feed with HFD for 12 weeks and treated orally with MA and MR for 6 weeks post-induction. FHD/OR: Rats feed HFD and treated orally for 6 weeks with standard drug OR. Statistical analysis is carried out using SPSS computer program, combined with costate computer program, where unshared letter is statistically significant at $P \leq 0.05$. MA: Morus alba, MR: Morus rubra, HFD: High-fat diet, PAI: Plasminogen activator inhibitor, OR: Orlistat

Table 2: Effects of MA and MR on ICAM, VCAM, and CRP in obese and therapeutic groups

\begin{tabular}{|c|c|c|c|c|c|c|c|}
\hline \multirow[t]{2}{*}{ Marker } & \multicolumn{7}{|l|}{ Groups } \\
\hline & Control/ND & Control/MA & Control/MR & HFD & HFD/MA & HFD/MR & HFD/OR \\
\hline ICAM (ng/ml) & $220.12^{\mathrm{a}} \pm 11.24$ & $217.00^{\mathrm{a}} \pm 7.80$ & $210.00^{\mathrm{a}} \pm 9.11$ & $590.00^{\mathrm{a}} \pm 13.00$ & $416.14^{b} \pm 15.00$ & $423.69^{b} \pm 18.66$ & $382.41^{\mathrm{b}} \pm 12.55$ \\
\hline$\%$ change & & 1.44 & 4.82 & 168.04 & 89.05 & 92.48 & 73.73 \\
\hline \%improvement & & & & & 78.98 & 75.55 & 94.3 \\
\hline VCAM (Pg/ml) & $1.10^{\mathrm{c}} \pm 0.09$ & $1.05^{c} \pm 0.12$ & $1.0^{c} \pm 0.23$ & $3.87^{c} \pm 0.99$ & $2.90^{\mathrm{e}} \pm 0.21$ & $2.51^{\mathrm{e}} \pm 0.77$ & $2.33^{\mathrm{e}} \pm 0.29$ \\
\hline$\%$ change & & 4.55 & 9.1 & 251.82 & 163.63 & 128.18 & 111.82 \\
\hline $\mathrm{CRP}(\mathrm{Pg} / \mathrm{ml})$ & $9.15^{\mathrm{i}} \pm 0.89$ & $9.00^{\mathrm{i}} \pm 0.15$ & $9.23^{\mathrm{i}} \pm 0.29$ & $18.76^{\mathrm{f}} \pm 1.23$ & $14.05^{j} \pm 1.26$ & $13.20^{i} \pm 0.96$ & $12.90^{i} \pm 0.69$ \\
\hline$\%$ change & - & 1.64 & 99.73 & 105.03 & 53.55 & 44.26 & 40.98 \\
\hline \%improvement & & & & & 51.48 & 60.76 & 64.26 \\
\hline
\end{tabular}

ND: Normal diet, ND/MA and ND/MR: Rats feed normal diet and treated orally with MA and MR extract for 6 weeks. HFD/MA and HFD/MR: Rats feed with HFD for 12 weeks and treated orally with MA and MR for 6 weeks post-induction. FHD/OR: Rats feed HFD and treated orally for 6 weeks with standard drug OR. Statistical analysis is carried out using SPSS computer program, combined with costate computer program, where unshared letter is statistically significant at $P \leq 0.05$. MA: Morus alba, MR: Morus rubra, HFD: High-fat diet, OR: Orlistat, ICAM: Intracellular cell adhesion molecule-1, VCAM: Vascular cell adhesion molecule-1, CRP: C-reactive protein

Table 3: Effects of MA and MR on Col II, Col 3A1, and LXO in obese rats and therapeutic groups

\begin{tabular}{|c|c|c|c|c|c|c|c|}
\hline \multirow[t]{2}{*}{ Parameters } & \multicolumn{7}{|l|}{ Groups } \\
\hline & Control/ND & Control/MA & Control/MR & HFD & HFD/MA & HFD/MR & HFD/OR \\
\hline Col II (ng/ml) & $20.30^{\mathrm{a}} \pm 1.28$ & $19.00^{\mathrm{a}} \pm 1.20$ & $19.80^{\mathrm{a}} \pm 1.50$ & $45.00^{\mathrm{b}} \pm 3.70$ & $26.31^{\mathrm{g}} \pm 1.64$ & $25.33^{\mathrm{g}} \pm 2.10$ & $27.21^{\mathrm{g}} \pm 1.78$ \\
\hline \%improvement & & & & & 92.07 & 96.89 & 87.64 \\
\hline Col 3A1 (ng/ml) & $12.29^{c} \pm 1.01$ & $12.00^{\mathrm{c}} \pm 1.20$ & $12.55^{\mathrm{c}} \pm 1.10$ & $30.00^{\mathrm{d}} \pm 1.90$ & $15.00^{\mathrm{e}} \pm 0.99$ & $12.66^{\mathrm{h}} \pm 1.10$ & $18.92^{\mathrm{h}} \pm 2.00$ \\
\hline$\%$ change & - & 2.35 & 2.12 & 144.1 & 22.05 & 3.01 & 53.94 \\
\hline \%improvement & & & & & 122.05 & 141.09 & 90.15 \\
\hline LOX & $0.50^{\mathrm{i}} \pm 0.03$ & $0.55^{\mathrm{i}} \pm 0.04$ & $0.50^{i} \pm 0.02$ & $1.12^{\mathrm{f}} \pm 0.07$ & $0.80^{j} \pm 0.05$ & $0.70^{\dagger} \pm 0.03$ & $0.72^{j} \pm 0.06$ \\
\hline$\%$ change & & 10 & 0 & 124 & 60 & 40 & 44 \\
\hline \%improvement & & & & - & 64 & 84 & 80 \\
\hline
\end{tabular}

ND: Normal diet, ND/MA and ND/MR: Rats feed normal diet and treated orally with MA and MR extract for 6 weeks. HFD/MA and HFD/MR: Rats feed with HFD for 12 weeks and treated orally with MA and MR extract for 6 weeks post-induction. FHD/OR: Rats feed HFD and treated orally for 6 weeks with standard drug OR. Statistical analysis is carried out using SPSS computer program, combined with costate computer program, where unshared letter is statistically significant at $P \leq 0.05$. MA: Morus alba, MR: Morus rubra, HFD: High-fat diet, OR: Orlistat, Col II: Collagen type II, Col 3A1: Collagen alpha-1(III) chain, LOX: Lipoxygenase

was proposed that the expression of the adiponectin receptors maybe affected by the high insulin levels due to HFD [17].

Further, the present results declared a significant reduction in glucagon level in HFD-treated rats. Experimental obesity has been induced by HFD, and the body weight gain is positively correlated with the content of dietary fat [18]. Moreover, obesity may be developed in many species of rodent connected with different metabolic syndrome, including glucose intolerance, insulin resistance, and dyslipidemia [19]. The cause why a HFD induced the inhibition in the incidence of diabetes is considered to be plasma glucagon-like peptide-1 (GLP-1) elevation levels in the rats with HF; GLP-1 is the major intestinal hormone secreted in response to ingestion of nutrient, and it not only stimulates insulin secretion but also inhibits gastric emptying, food intake, and glucagon secretion [18].

In addition, our results clearly indicated a significant increase in troponin level in serum of obese rats. In concomitant with the present results, De Martini et al. [20] illustrated proposed that obesity affects cardiac function and leads to cardiac injury, and plasma and cardiac troponin were elevated in obese mice at baseline compared to non- 


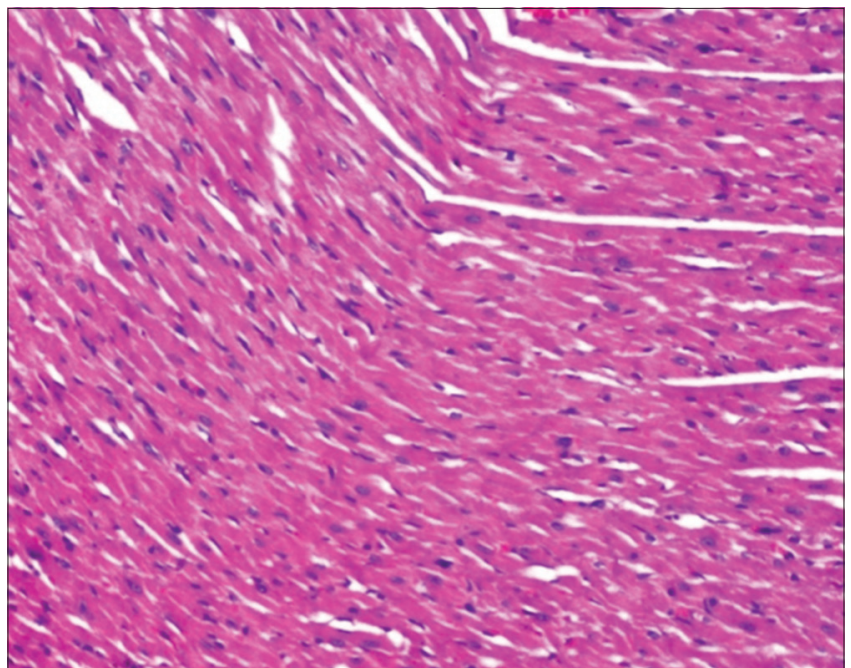

Photomicrograph 1: Normal histopathological structure of the myocardial bundles of control rats

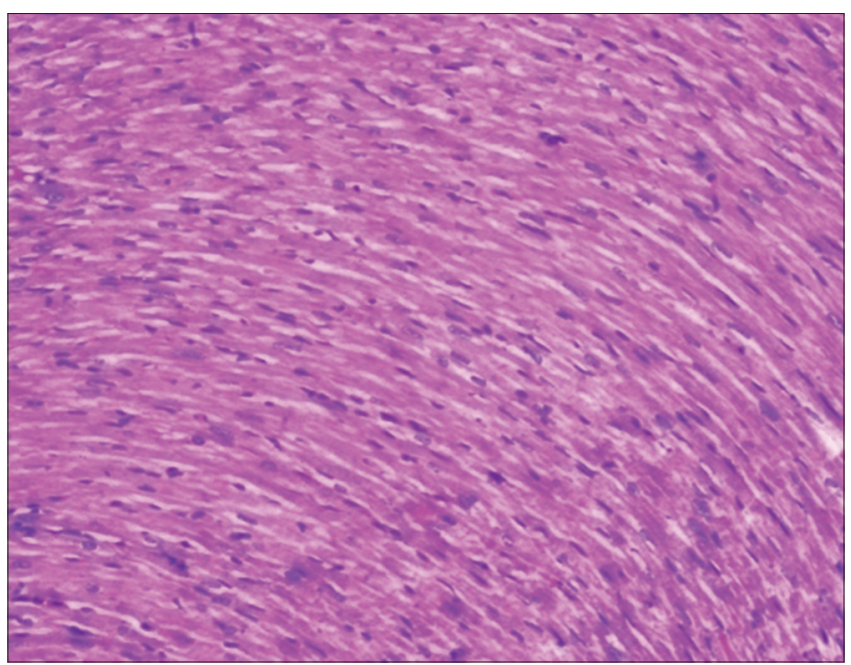

Photomicrograph 2: No histopathological alteration in obese cardiac tissue post-treated with Morus alba

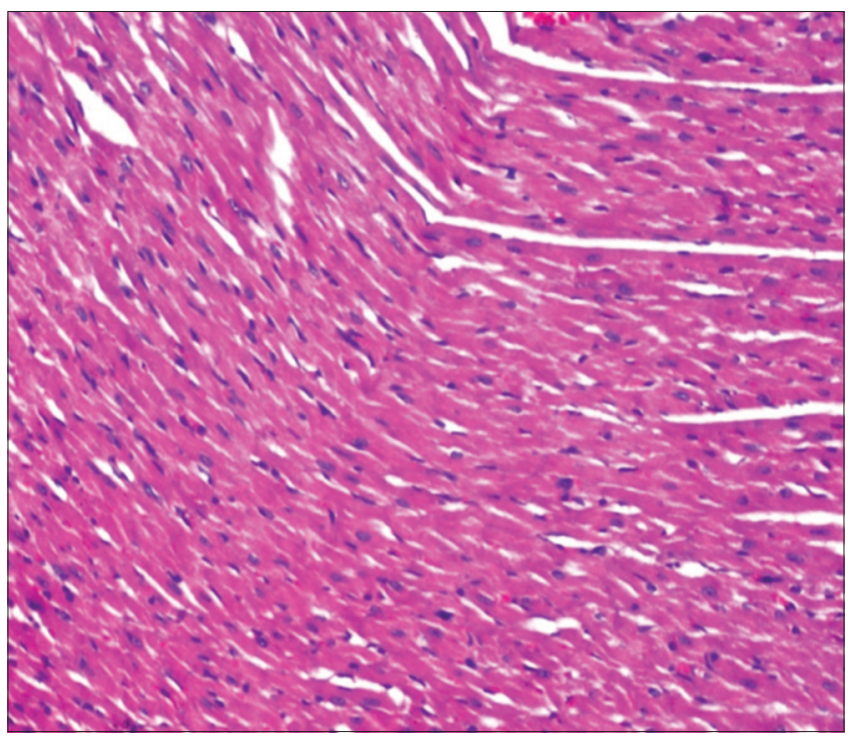

Photomicrograph 3: Normal histological structure in myocardial bundles in obese rats post-treated with Morus rubra

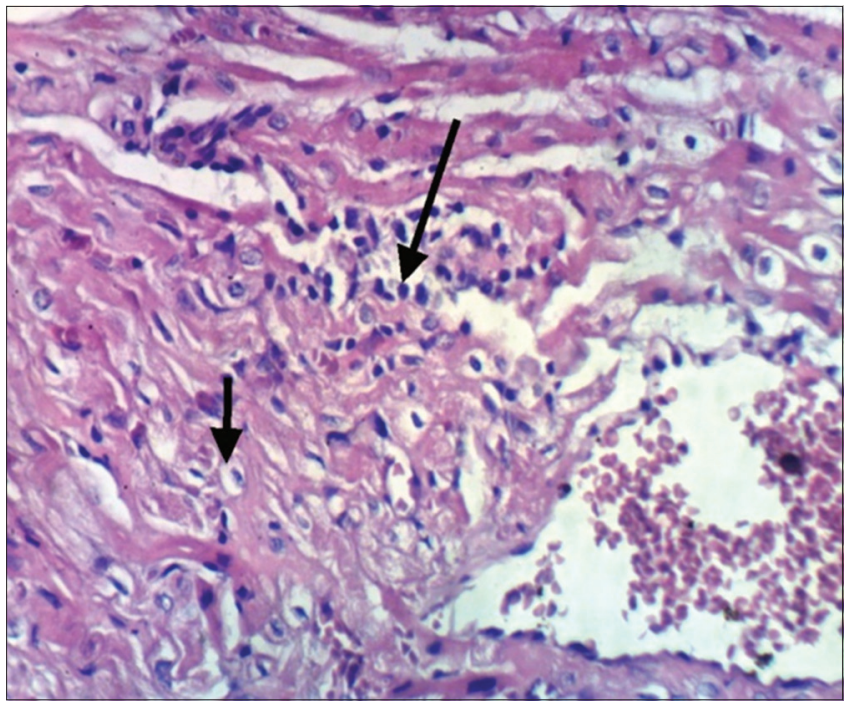

Photomicrograph 4: Heart of obese rat showing vacuolation of the sarcoplasm of cardiac myocytes, focal fibrosis of cardiac myocytes associated with inflammatory cells infiltration $(\mathrm{H}$ and $\mathrm{E}, \times 400)$

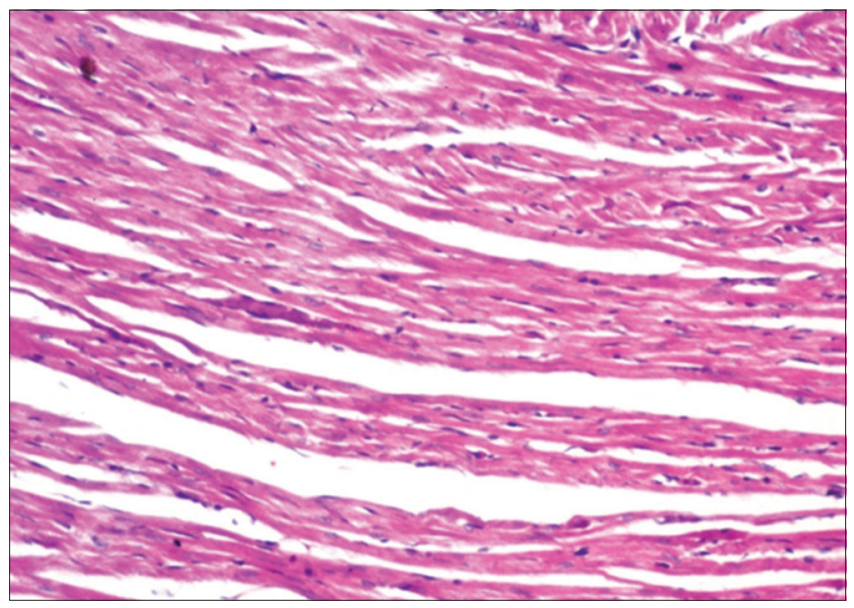

Photomicrograph 5: No histopathological alteration in cardiac tissue of obese rats post-treated with Morus alba

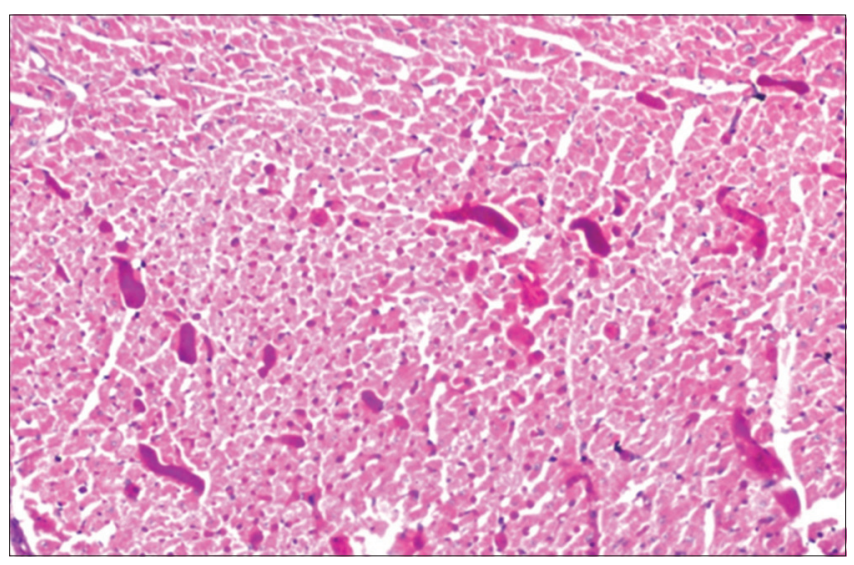

Photomicrograph 6: No histopathological alteration in cardiac tissue of obese rats post-treated with Morus rubra

obese mice. Cardiac hypertrophy is a very early consequence of dietinduced obesity, apparent early and accompanied by substantial cardiac dysfunction [21]. Troponin I may be elevated due to HFD-promoted 


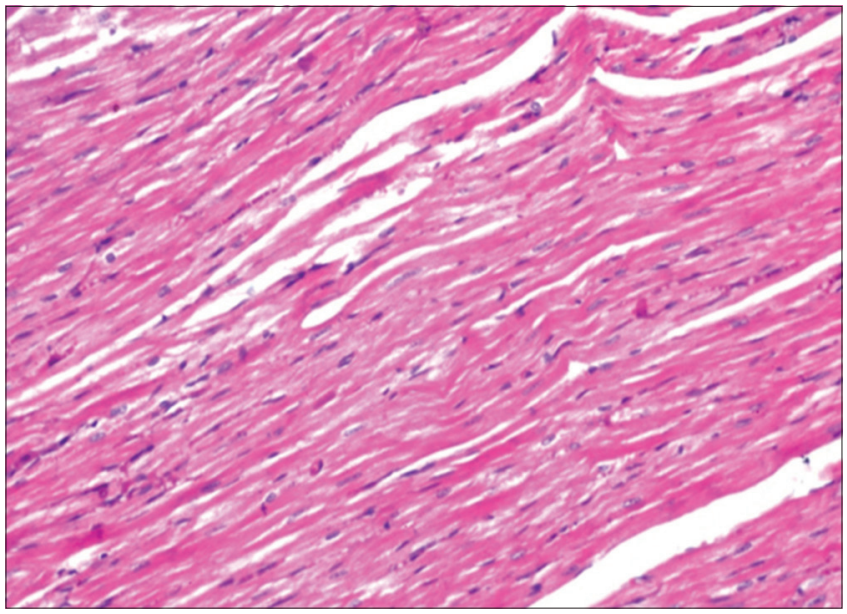

Photomicrograph 7: No histopathological alteration in cardiac tissue of obese rats post-treated with standard drug

adaptations of mitochondrial for increased fatty acids utilization, which was, however, not enough to prohibit the myocardial lipid accumulation and lipid intermediates. Accumulation of myocardial lipid is connected with oxidative stress and fibrosis but not with apoptosis. Furthermore, the phosphorylation of phospholamban which is a prominent regulator of cardiac calcium homeostasis and contractility was strongly affected and reduced by HFD. Hence, cardiomyopathy induced by HFD in mice is associated with lipotoxicity-generated oxidative stress, fibrosis, and impaired calcium homeostasis, rather than deteriorated cardiac energetics [22].

Moreover, the current results showed significant elevation in API-1 in the serum of obese rats. The increment in PAI-1 level is considered a mechanistic pathway through which obesity contributes to increase cardiovascular disease risk. Abdominal adipose tissue specifically is a major PAI-1 source with visceral adipose tissue (VAT), generally considered to produce more PAI- 1 than subcutaneous adipose tissue. However, this does not necessarily lead to increased plasma PAI-1 levels. Hence, the relationship between VAT and plasma PAI-1 levels is not fixed but can be modulated by a number of factors such as the size of the subcutaneous adipose tissue depot, ethnicity, possibly genetics, and other obesity-related metabolic abnormalities [23]. Furthermore, we noticed a significant increase in VACM, ICAM, and CRP in serum of obese rats. Freeman [24] explained that cerebrovascular changes including high level of ICAM and VCAM as well as increase in inflammatory markers, CRP, occur due to a HFD-induced obesity and the mechanisms involved may be due to altered cerebral blood flow, hyperlipidemia, oxidative stress, and inflammation. Adipose tissue that secret multiple proteins, factors, and hormones into the circulation are collectively known as adipokines. Adipokines exert pleiotropic effects on target tissues/organs, thereby regulating energy homeostasis, metabolism, and insulin sensitivity, as well as immune and cardiovascular functions. Expanding adipose tissue in obesity undergoes a change in the adipokine secretion profile characterized by an increase of pro-inflammatory adipokines and suppression of anti-inflammatory adipokines increasing proinflammatory pathways within adipose tissue depots and creating an adverse circulating adipokine profile, resulting in a chronic, lowgrade, systemic inflammatory state. Kyrou et al. [25] evidenced the directly links of the adverse pro-inflammatory adipokine profile in obesity with several cardiometabolic effects as myocardial insulin resistance, hypertension, atherosclerosis, and endothelial and cardiac dysfunction.

In a good connection with our histopathological findings, Chen et al. [26] speculated that HFD rats exhibited cardiac fibrosis and enhanced lipid accumulation and inflammation without affecting cardiac morphology in the heart of rat, supposing that interleukin (IL)-6 engages to regulate lipid metabolic disorder, cardiac hypertrophy, fibrosis, inflammation, and myocardium lipotoxicity during obesity induced by HFD.

The results of the present research showed a significant increase in both collagen type fractions 11 and 111 in serum of obese rats. No information was found in the literature as a possible explanation for this findings which detected for the first time in this study. However, Silva et al. [27] declared a possible explanation for the reduction in collagen fraction 1 and related to the decrease in the synthesis and/ or an increase in degradation of collagen 1. Besides, adipose tissue secretes several substances that are implicated in the myocardial collagen regulation, such as leptin, which is released by adipocytes and is manufactured by various tissues including the heart [28]. A clear relation between obesity and heart failure exists and a significant role for leptin, the product of the obese gene, has been suggested. One aspect of myocardial remodeling which characterizes heart failure is a disruption in the balance of extracellular matrix synthesis and degradation. Leptin regulates cardiomyocyte hypertrophy and adjusts output of the different components to the extracellular matrix of the myocardium that act on cardiac fibroblasts. It is possible that increased activity of both matrix metallopeptidase 2 (MMP-2) and MMP-9 is responsible for the reduction in myocardial collagen type I. In controversy with the present results, Silva et al. [27] showed that myocardial collagen type III did not change in obesity.

In parallel with our results, Carroll et al. [29] explained that a HFD for a 12 -week period causes fibrosis in coronary vessels, as well as accumulation of collagen in the cardiac interstitium. The mechanisms underlying the accumulation of collagen in animals remain unknown; Leopoldo et al. [30] proposed that the higher levels of collagen are associated with anomaly in insulin metabolism. Insulin growth factor induces transforming growth factor beta-1, which directly stimulates collagen expression. However, given that obesity also has been linked with cardiac fibrosis through elevation of some factors implicated in the development of cardiac fibrosis such as cytokines, endothelin, and renin-angiotensin-aldosterone [30]. The same authors added that obesity promotes pathological myocardial fibrosis and damage to the myocardial ultrastructure, as indicated in the present study (Photomicrograph 4).

The current results also indicated a significant increase in LOX in obese rats; Chakrabarti et al. [31] proposed that low-grade inflammation is a leading cause of obesity and promotes type 2 diabetes and cardiovascular disease in obese individuals. The 12- and 5-LOX (12LXO and 5-LXO) enzymes have been connected with inflammatory alterations, causing atherosclerosis development.

On the other hand, treatment of obese rats with MAF and MRF extracts exhibited marked improvement in aforementioned biomarkers, especially with MRF extract which demonstrated higher percentages of improvement than standard drug. These findings may be explained by mulberry leaf extract (MLE) exhibited its useful effect on lipid profiles regulation and the atherogenic index, joined with reduction of fat accumulation in the liver [8]. Moreover, MLE decreased fibrosis of hepatic tissue as examined by collagen gene expressions. In addition, medication with MLE improved oxidative stress and metabolic abnormalities in obese subjects induced by HFD, due to its strong antioxidative [32], anti-obesity, and anti-inflammatory effects [1,33]. In addition, Ann et al. [8] declared that mulberry leaf has different biological effects including free radicals scavenging, oxidation inhibition, and atherogenic risk-reducing activities, related to several polyphenolic compounds such as DNJ-1 and resveratrol. These compounds were demonstrated to exhibit anti-obesity activities by blocking preadipocytes differentiation [8] and activating $\beta$-oxidation system [8]. Previously, DNJ-rich MLE has been effectively used to ameliorate lipid profiles in human subjects [34] and to inhibit accumulation of lipid through stimulation of $\beta$-oxidation [8]. In addition, resveratrol is characteristic by its ability to reduce reactive oxygen species (ROS) and activate oxidation of fatty acid [35]. Further, medication with MLE 
considerably modulated the HFD-induced accumulation of hepatic lipid through the suppression in lipogenesis process and the enhancement in lipolysis in HFD-induced non alcoholic fatty liver disease (NAFLD). Accumulation of hepatic lipid is also regulated by gene expression induction implicated in energy expenditure and oxidation of fatty acids through increasing degradation of lipid and energy metabolism [8].

Park et al. [36] illustrated that the mice with HFD were recognized by increasing hepatic fibrosis biomarkers such as $\alpha$-smooth muscle and type 1 collagen. Huang et al. [37] demonstrated that hepatic fibrosis and development of NAFLD are induced by differentiation of adipocyte and oxidative stress. The current study could give a clue for the first time on the beneficial effect of MA and MR extracts supplementation on cardiac dysfunction and fibrosis by attenuating ROS, vascular function, lipid accumulation, inflammation, and reduced collagen in the HFDinduced obesity.

In accordance with our results, Lim et al. [1] declared that mulberry fruit improves blood lipid profiles and lipid metabolism in hyperlipidemic rats. The same author added that excessive FFAs and saturated fatty acids from adipose tissue lead to fat accumulation in the liver and other tissues, resulting in an increased inflammatory reaction. Besides, fat accumulation in the liver increases LDL over production together with inflammatory cytokines, such as IL- 6 and CRP. Our results show that serum levels of CRP increased in HFD group but selectively decreased by both MFE treatments. Treatments with both MLE and MFE were effectively against obesity and its related inflammation and oxidative stress [1].

The presence of DNJ in the extract of mulberry leaf serves in normalization of serum adiponectin level and enhances AMPactivated protein kinase. These in turn activate ß-oxidation of fatty acids which inhibit hepatic lipid accumulation. Supplementation of MA fruits powder to rats recorded marked reduction in triglyceride, total cholesterol, LDL, and atherogenic index. Furthermore, powder of mulberry leaf can protect the cardiac function by attenuating oxidative stress, cellular infiltration, cardiac fibrosis and myocyte apoptosis. MA root extracts were shown to have anti-inflammatory efficacy [38]. MA butanol extract significantly decreased LPS-stimulated production of PGE2, TNF- $\alpha$, and cyclooxygenase 2 (COX-2) expression in RAW264.7 macrophages [39], while methanol extract of MA has different compounds with inducible nitric oxide synthase (iNOS) inhibitory activity which can correlate with its anti-inflammatory activities [38]. Morus bombycis extract exhibited anti-inflammatory and inhibitory activities on collagen-induced arthritis. Further, MAA root extract contains a large amount of cudraflavone $B$ which is a prenylated flavonoid and causes noticeable inhibition in inflammatory mediators in some in vitro models. It was a powerful TNF-a inhibitor by preventing the NF-kB translocation from the cytoplasm to the nucleus. The NF-Kb inhibition activity leads to an inhibition in the gene expressions of COX$2[40,41]$. Resveratrol purified from MA inhibits a secretion of IL-8 by blocking phosphorylation of MAPK and activation of NF-kappa B in LPSinduced human monocytic cell line THP-1 [38, 42]. Sanggenons C and O, isolated from MA, inhibit production of NO through induction of iNOS and nuclear factor activation in LPS-induced RAW264.7 cells indicating its anti-inflammatory efficiency [38]. The ameliorative effects of both berries are also documented at the cellular level in the present study, which declared no histopathological alterations compared to standard drug (Photomicrographs 5 and 7).

\section{CONCLUSION}

MA and MR extracts modulate obesity-induced cardiac dysfunction through inhibition of lipogenesis, fibrosis, and enhancement of lipolysis in obesity induced by HFD. Furthermore, MA and MR regulated vascular function, inflammatory markers, and lipid accumulation which considered as risk factors for protection and/or remediation of obesity-associated cardiac dysfunction. The present findings could provide an insight into the strategy development to protect and handle obesity in the future.

\section{AUTHOR'S CONTRIBUTIONS}

Farouk K. El-Baz: Plan of work, writing, revision, and corresponding author. Hanan F. Aly: Experimental animals, statistical analysis, and writing. Howaida I. Abd-Alla: Biochemical measurements and writing. Dalia F. Biomy: Sample preparation, preparation of extract for bioassays, and histological investigation.

\section{CONFLICTS OF INTEREST}

Authors declare no conflict of interest.

\section{REFERENCES}

1. Lim HH, Yang SJ, Kim Y, Lee M, Lim Y. Combined treatment of mulberry leaf and fruit extract ameliorates obesity-related inflammation and oxidative stress in high fat diet-induced obese mice. J Med Food 2013;16:673-80.

2. Rout SP, Choudary KA, Kar DM, Das L, Jain A. Plants in traditional medicinal system-future source of new drugs. Int J Pharm Pharm Sci 2009; $1: 1-23$

3. El-Baz FK, Aly HF, Abd-Alla HI. Berries supplementation modulates body weight and metabolic deteriorations in obese rats. Asian J Pharm Clin Res 2018;11:322-8.

4. Rao SJ, Ramesh CK, Mahmood R, Prabhakar BT. Anthelmintic and antimicrobial activities in some species of mulberry. Int J Pharm Pharm Sci 2012;4:335-8.

5. Lee CY, Cheng HM, Sim SM. Mulberry leaves protect rat tissues from immobilization stress-induced inflammation. Biofactors 2007;3:25-33.

6. Ou TT, Hsu MJ, Chan KC, Huang CN, Ho HH, Wang CJ. Mulberry extract inhibits oleic acid-induced lipid accumulation via reduction of lipogenesis and promotion of hepatic lipid clearance. J Sci Food Agric 2011;91:2740-8.

7. Azman KF, Amom Z, Azlan A, Esa NM, Ali RM, Shah ZM, et al. Antiobesity effect of Tamarindus indica L. pulp aqueous extract in high-fat diet-induced obese rats. J Nat Med 2012;66:333-42.

8. Ann JY, Eo H, Lim Y. Mulberry leaves (Morus alba L.) ameliorate obesity-induced hepatic lipogenesis, fibrosis, and oxidative stress in high-fat diet-fed mice. Genes Nutr 2015;10:1-13.

9. Adaramoye O, Akinatyo O, Achen J, Michel A. Lipid lowering effects of methanolic extracts of Vernonia anygdalina leaves in rats fed on high cholesterol diet. Vasc Health Risk Manag 2008;4:235-41.

10. Shalaby HM, Tawfek NS, Abo-El Hussein BK, Abd El-Ghany MS. The assessment of some biochemical and immunological effects by amphetamine and orlistat on obesity in rats. Food Public Health 2015;4:185-92.

11. Hwang YJ, Lee EJ, Kim HR, Hwang KA. In vitro antioxidant and anticancer effects of solvent fractions from Prunella vulgaris var. Lilacina. BMC Complement Altern Med 2013;13:310.

12. Selek S, Aslan M, Nazligul Y. Serum PON1 activity and oxidative stress in non-alcoholic fatty liver disease. J Harran Univ Med Fac 2012;9:85-91.

13. Drury RA, Wallington EA. Carleton's Histology Technique. $4^{\text {th }}$ ed. New York: Oxford University Press; 1980. p. 653-61.

14. Davidson EP, Coppey LJ, Calcutt NA, Oltman CL, Yorek MA. Dietinduced obesity in sprague-dawley rats causes microvascular and neural dysfunction. Diab Metab Res Rev 2010;26:306-18.

15. Davidson EP, Coppey LJ, Dake B, Yorek MA. Effect of treatment of Sprague dawley rats with AVE7688, enalapril, or candoxatril on dietinduced obesity. J Obesity 2011;2011:pii: 686952.

16. Marques C, Meireles M, Norberto S, Leite J, Freitas J, Pestana D, et al. High-fat diet-induced obesity rat model: A comparison between wistar and Sprague-dawley rat. Adipocyte 2016;5:11-21.

17. Bullen JW Jr., Bluher S, Kelesidis T, Mantzoros CS. Regulation of adiponectin and its receptors in response to development of diet-induced obesity in mice. Am J Physiol Endocrinol Metab 2007;292:1079-86.

18. Aly HF, Abd-Alla HI, Ali SA, Aba-Alez R, Abu-Krisha MT, Mohamed MM. Bioinformatics: inflammatory cytokines and attenuation of diabetes hypercholesterolemia-induced renal injury using morning glory and necklace pod extracts. Asian J Pharm Clin Res 2017; $10: 347-55$

19. Wang H, Storlien LH, Huang XF. Effects of dietary fat types on body fatness, leptin, and ARC leptin receptor, NPY, and AgRP mRNA expression. Am J Physiol Endocrinol Metab 2002;282:E1352-9.

20. De Martini T, Nowell M, James J, Williamson L, Lahni P, Shen H, et al. High fat diet-induced obesity increases myocardial injury and alters cardiac STAT3 signaling in mice after polymicrobialsepsis. Biochim 
Biophys Acta 2017;1863:2654-60.

21. Si LY, Ali SA, Latip J, Fauzi NM, Budin SB, Zainalabidin S. Roselle is cardio protective in diet-induced obesity rat model with myocardial infarction. Life Sci 2017;191:157-65.

22. Abdurrachim D, Ciapaite J, Wessels B, Nabben M, Luiken JJ, Nicolay K, et al. Cardiac diastolic dysfunction in high-fat diet fed mice is associated with lipotoxicity without impairment of cardiac energetics in vivo. Biochim Biophys Acta 2014;1842:1525-37.

23. Barnard SA, Pieters M, De Lange Z. The contribution of different adipose tissue depots to plasma plasminogen activator inhibitor-1 (PAI-1) levels. Blood Rev 2016;30:421-9.

24. Freeman LR. Cerebrovascular Changes: The Role of fat and Obesity. Omega-3 Fatty Acids in Brain And Neurological Health. New York: Academic Press; 2014. p. 221-9.

25. Kyrou I, Mattu HS, Chatha K, Randeva HS. Fat Hormones, Adipokines. Endocrinology of the Heart in Health and Disease. Amsterdam: Academic Press; 2017. p. 167-205.

26. Chen F, Chen D, Zhao X, Yang S, Li Z, Sanchis D, et al. Interleukin-6 deficiency facilitates myocardial dysfunction during high fat dietinduced obesity by promoting lipotoxicity and inflammation. Biochim Biophys Acta 2017;1863:3128-41.

27. Silva DC, Lima-Leopoldo AP, Leopoldo AS, Campos DH, Nascimento AF, Oliveira SA Jr., et al. Influence of term of exposure to high-fat diet-induced obesity on myocardial collagen Type I and III. Arq Bras Cardiol 2014;102:157-64.

28. Schram K, De Girolamo S, Madani S, Munoz D, Thong F, Sweeney G. Leptin regulates MMP-2, TIMP-1 and collagen synthesis via p38 MAPK in HL-1 murine cardiomyocytes. Cell Mol Biol Lett 2010;15:551-63.

29. Carroll JF, Tyagi SC. Extracellular matrix remodeling in the heart of the homocysteinemic obese rabbits. Am J Hypertens 2005;18:692-8.

30. Leopoldo AS, Sugizaki MM, Lima-Leopoldo AP, do Nascimento AF, Luvizotto Rde A, de Campos DH, et al. Cardiac remodeling in a rat model of diet-induced obesity. Can J Cardiol 2010;26:423-9.

31. Chakrabarti SK, Wen Y, Dobrian AD, Cole BK, Ma Q, Pei H, et al. Evidence for activation of inflammatory lipoxygenase pathways in visceral adipose tissue of obese zucker rats. Am J Physiol Endocrinol Metab 2011;300:175-87.

32. Aramwit P, Supasyndh O, Siritienthong T, Bang N. Mulberry leaf reduces oxidation and $\mathrm{C}$-reactive protein level in patients with mild dyslipidemia. Biomed Res Int 2013;2013:787981

33. Peng CH, Liu LK, Chuang CM, Chyau CC, Huang CN, Wang CJ. Mulberry water extracts possess an anti-obesity effect and ability to inhibit hepatic lipogenesis and promote lipolysis. J Agric Food Chem 2011;59:2663-71.

34. Doi K, Kojima T, Fujimoto Y. Mulberry leaf extract inhibits the oxidative modification of rabbit and human low density lipoprotein. Biol Pharm Bull 2000;23:1066-71.

35. Liu GS, Zhang ZS, Yang B, He W. Resveratrol attenuates oxidative damage and ameliorates cognitive impairment in the brain of senescence-accelerated mice. Life Sci 2012;91:872-7.

36. Park S, Choi Y, Um SJ, Yoon SK, Park T. Oleuropein attenuates hepatic steatosis induced by high-fat diet in mice. J Hepatol 2011;54:984-93.

37. Huang GC, Zhang JS, Tang QQ. Involvement of C/EBP-alpha gene in vitro activation of rat hepatic stellate cells. Biochem Biophys Res Commun 2004;324:1309-18.

38. Priya S. Medicinal values of mulberry-an overview. J Pharm Res 2012;5:3588-96.

39. Choi EM, Hwang JK. Effects of Morus alba leaf extract on the production of nitric oxide, prostaglandin E2 and cytokines in RAW264.7 macrophages. Fitoterapia 2005;76:608-13.

40. Hosek J, Bartos M, Chudik S, DallAcua S, Innocenti G, Kartal M, et al. Natural compound cudraflavone B shows promising anti-inflammatory properties in vitro. J Nat Prod 2011;74:614-9.

41. Kim HJ, Lee HJ, Jeong SJ, Lee HJ, Kim SH, Park EJ. Cortex mori radicis extract exerts antiasthmatic effects via enhancement of CD4(+) CD25(+)Foxp3(+) regulatory T cells and inhibition of Th2 cytokines in a mouse asthma model. J Ethnopharmacol 2011;138:40-6.

42. Oh YC, Kang OH, Choi JG, Chae HS, Lee YS, Brice OO, et al. Anti-inflammatory effect of resveratrol by inhibition of IL-8 production in LPS-induced THP-1 cells. Am J Chin Med 2009;37:1203-14. 